\title{
Geoturismo como Estratégia de Geoconservação para a praia de Pedra do Sal, Parnaíba/PI
}

\author{
Geotourism as Geoconservation strategy for the Pedra do Sal beach, Parnaíba / PI \\ Silva $^{1}$, B. R. V.; Baptista ${ }^{2}$, E. M. C. \\ rafaele.14@hotmail.com;
}

\begin{abstract}
Resumo
Parte da população nacional reside em zonas costeiras, onde se encontram núcleos essenciais da dinâmica demográfica brasileira, na qual esta parcela é responsável pelo uso excessivo de seus recursos, acarretando consequências para essas áreas. O objetivo da pesquisa constituiu-se em analisar o geoturismo como estratégia da geoconservação para a praia de Pedra do Sal, na zona costeira do estado do Piauí. Configurando-se como uma pesquisa de abordagem qualitativa e quantitativa, neste estudo foram utilizados os seguintes procedimentos metodológicos: pesquisa bibliográfica, pesquisa documental e pesquisa de campo. Evidencia-se nesse contexto, a praia de Pedra do Sal, que possui atrativos geoturísticos de interesse para a geoconservação, como o promontório rochoso e duas faixas praiais distintas. A maioria dos participantes da pesquisa sugeriram que para uma melhor conservação da praia, deveria ser implementado um novo tipo de turismo que viabilizasse ideias de proteção ambiental, sendo o Geoturismo adequado a essa finalidade. Espera-se assim, contribuir para a ampliação dos conhecimentos acerca da zona costeira piauiense, relacionados, notadamente, à pratica geoturística visando a geoconservação e valorização da praia estudada.
\end{abstract}

Palavras-chave: Geoconservação. Geoturismo. Praia de Pedra do Sal.

\begin{abstract}
Part of the national population lives in coastal areas, where essential core of the Brazilian population dynamics, in which this part is responsible for excessive use of its resources, leading to numerous consequences for these areas. The objective of the research is to analyse geotourism as the geoconservation strategy for the Pedra do Sal beach, in the coastal zone of the state of Piaui. With a qualitative and quantitative approach this study used the following methodological procedures: bibliographic, documentary and field research. It is evident in this context, the beach of Pedra do Sal, which offers geotouristic attractions of interest to geoconservation as the rocky promontory and the two distinct praiais tracks. Most survey participants suggested that for better conservation of the beach, should be implemented a new type of tourism that make feasible environmental protection ideas, and the Geotourism suitable for this purpose. It is expected to contribute to the expansion of knowledge about the Piaui coastline, related, mainly, to geotouristic practices aimed at better ways of geoconservation and enhancement of the studied beach
\end{abstract}

Keywords: Geoconservation. Geotourism. Pedra do Sal beach.

\section{INTRODUÇÃO}

As zonas costeiras representam um sistema economicamente produtivo, e se caracterizam pela complexidade das atividades que abrigam, bem como pela sensibilidade de seus ecossistemas (GREGÓRIO, 2009), dessa forma, o crescimento da população nesta região resulta na exploração e degradação destes ambientes (PEREIRA, JIMENÉZ E MEDEIROS, 2003).

Constituem áreas nas quais a maior parcela da população brasileira se aloca, compondo núcleos essenciais da dinâmica demográfica do país (MORAES, 2007), sendo seus recursos utilizados de forma exagerada e inconsequente por parte desta parcela com significativas implicações. 
A zona costeira do Piauí apresenta-se como possuidora de riquezas naturais, por meio de seus ecossistemas, constituindo-se assim como um patrimônio natural das comunidades que ali se desenvolvem. Entretanto, esse patrimônio natural piauiense encontra-se ameaçado, pelo uso e ocupação desenfreada de seus recursos, no qual não se está dando a devida importância para a sua proteção e conservação.

A praia da Pedra do Sal está situada no município de Parnaíba, porção leste da ilha Grande de Santa Isabel, ilha fluvial do Delta do rio Parnaíba (FUNDAÇÃO CEPRO, 1996). Destaca-se então a área de estudo da presente pesquisa, por se tratar da única praia da cidade de Parnaíba, denotando-se assim a sua importância econômica, social e ambiental para o município.

Deste modo, o objetivo da pesquisa constituiu-se em analisar o geoturismo como estratégia da geoconservação para a praia de Pedra do Sal, na zona costeira do estado do Piauí.

O geoturismo é inserido como tentativa de conservação, valorização, bem como divulgação do potencial geológico-geomorfológico da praia de Pedra do Sal, tendo como viabilidade a prática geoturística como subsídio para o processo de geoconservação na referida praia. A realização de pesquisas nessa temática é relevante em função da necessidade de ampliar os estudos sobre essa nova abordagem geoturística e geoconservacionista em áreas litorâneas, em especial a praia de Pedra do Sal.

\section{METODOLOGIA}

Configurando-se como uma pesquisa de abordagem qualitativa e quantitativa, para dar suporte a este estudo foram utilizados os seguintes procedimentos metodológicos: pesquisa bibliográfica, pesquisa documental e pesquisa de campo. Neste trabalho, o estudo bibliográfico foi realizado através de artigos, dissertações e teses; a pesquisa documental foi feita baseada em relatórios técnicos elaborados sobre a área.

Neste estudo empregou-se a pesquisa de campo para caracterização geral da praia de Pedra do Sal, por meio de preenchimento de roteiro previamente elaborado, fazendo uso da observação estruturada e levantamento fotográfico, aplicação de questionários e entrevistas, tendo em vista a constatação da aplicação do geoturismo para a referida praia. Foram feitas quatro visitas à praia, durante os meses de fevereiro a novembro de 2015.

Nesta pesquisa realizou-se a aplicação de questionários apenas com os residentes usuários, turistas e visitantes da praia em questão. Obteve-se como universo da pesquisa a quantidade de trinta estabelecimentos existente na área próxima à praia, sendo vinte e oito bares e restaurantes, e duas pousadas. Desse total, foi estabelecida uma amostra de 30\% para aplicação de dez 
questionários com a população residente apenas no entorno da praia que se constituem em funcionários dos estabelecimentos. Em relação aos turistas e visitantes, o questionário foi aplicado com todos que frequentavam a praia durante a pesquisa, totalizando 8 participantes.

\section{RESULTADOS E DISCUSSÃO}

\section{1: Aspectos naturais da praia de Pedra do Sal}

A praia de Pedra do Sal inserida entre as coordenadas $02^{\circ} 48^{\prime} 14,9^{\prime \prime}$ de Latitude Sul e $41^{\circ}$ 43' 43,5" de Longitude Oeste, localiza-se na ilha Grande de Santa Isabel, pertencendo ao município de Parnaíba, estando a $18 \mathrm{~km}$ do centro da cidade e que dista cerca de $318 \mathrm{~km}$ de Teresina, capital do estado do Piauí.

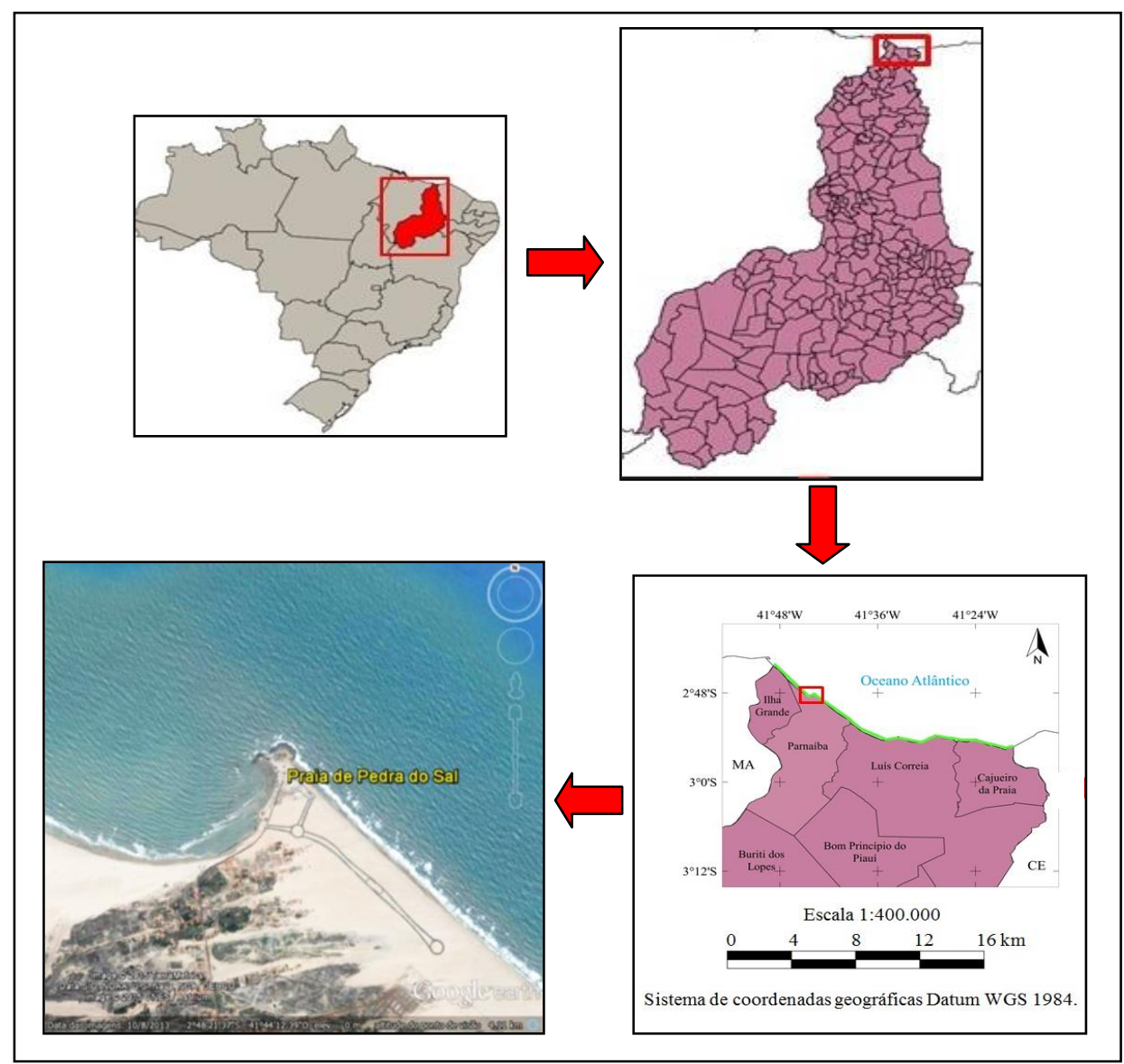

Figura 01. Localização da área de estudo. Fonte: Silva (2016)

A referida praia está inserida na Área de Proteção Ambiental (APA) do Delta do rio Parnaíba (IBIAPINA et al, 2013) sendo a única situada no município de Parnaíba. Segundo Silva (2013) o nome Pedra do Sal vem das formações de sal nas cavidades das pedras graníticas, em 
virtude da evaporação das águas salgadas nelas depositadas e das suas espumas brancas, que decoram a paisagem natural do litoral piauiense.

Sobre a praia, Baptista (1981, p. 126) registra que esta "é formada por dois rochedos, um junto à costa e outro ao largo". Gama Junior, Gorayeb e Abreu (1988) em estudo, afirmaram que poucas são as informações geológicas encontradas sobre o promontório rochoso presente da referida praia. As relações geológicas de campo entre o granito Pedra do Sal e as rochas regionais adjacentes não são conhecidas, pois este corpo se encontra circundado por sedimentos praieiros recentes. A Formação Barreiras de idade Terciária tem distribuição areal importante recobrindo as regiões a Sul e Leste do local de afloramento do granito Pedra do Sal.

O promontório rochoso faz a separação da mesma em duas faixas praiais distintas: uma faixa a leste, a praia brava (fig. 02), com ondas violentas que sofrem influência da maré, que ao baterem nas rochas propiciam um espetáculo da natureza, e outra faixa a oeste, a praia mansa (fig. 03), de mar calmo e quase sem ondas onde se atracam canoas de pescadores. Sucessivas ressacas das marés vêm ao longo dos anos transformando o contorno da costa da praia, destruindo grande parte da pista construída anos atrás (IBIAPINA et al, 2013).

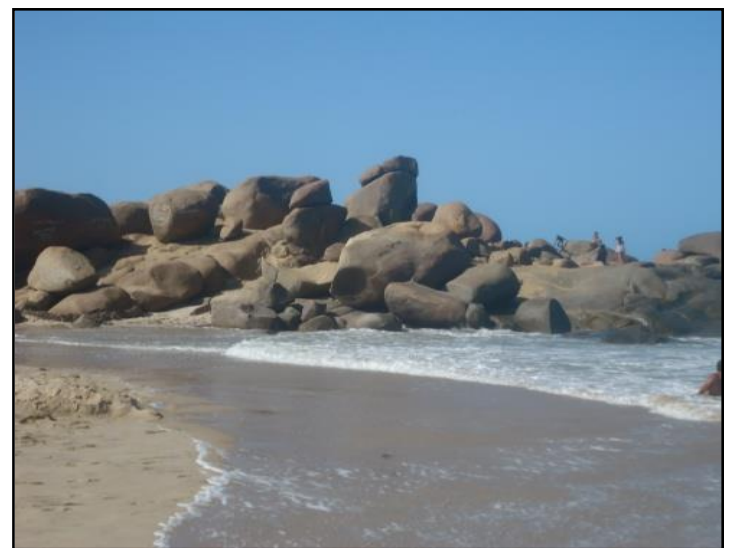

Figura 02. Faixa praial brava. Fonte: Silva (2016)

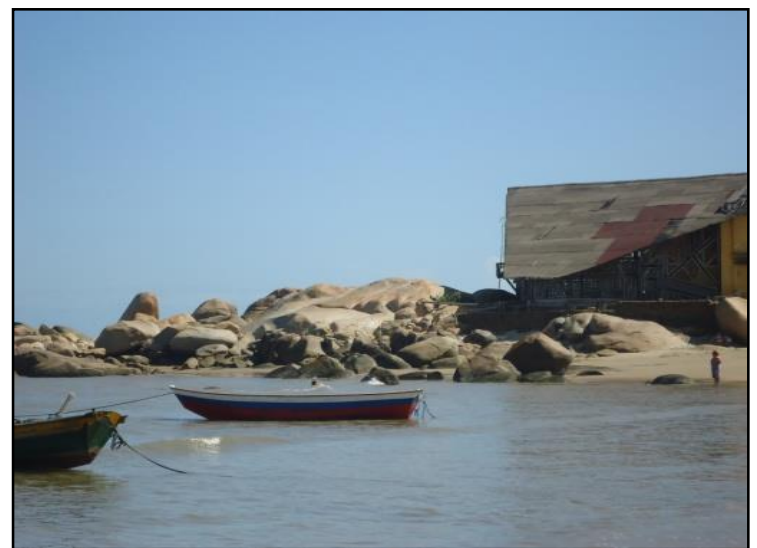

Figura 03. Faixa praial mansa. Fonte: Silva (2016)

De acordo com Reis e Baptista (2012) a área de estudo possui uma condição natural diferenciada em relação aos seus aspectos físicos das demais praias do litoral do Piaú, motivada pela influência de suas características geológicas e geomorfológicas, bem como em função da dinâmica do oceano que, em conjunto, propiciaram a formação de feições atípicas na região, conforme indica Baptista (2004, p. 175) ao afirmar que na Pedra do Sal os rochedos são “caracteristicamente de constituição granítica, originados por afloramento em decorrência das transgressões e regressões marinhas". Neste caso, pode-se evidenciar os rochedos como um dos protagonistas destas condições. 
A praia de Pedra do Sal apresenta relevantes aspectos naturais, a começar pelo principal atrativo da área, o promontório rochoso, que serve de proteção para a costa, destacando assim sua geodiversidade, bem como a biodiversidade lá existente, como peixes, moluscos, aves entre outros.

\subsection{Geoturismo na praia de Pedra do Sal}

As análises obtidas através dos questionários realizados com os dois públicos alvos da pesquisa, a saber: residentes usuários da praia de Pedra do Sal e os turistas e/ou visitantes da referida praia, expressam a compreensão de como estes percebem a praia, na perspectiva do Geoturismo para a conservação de seus recursos naturais.

De acordo com Silva (2013), a comunidade da Pedra do Sal é composta por aproximadamente 300 famílias, que vivem principalmente da pesca artesanal no mar e em lagoas adjacentes, da criação extensiva de gado e da venda de frutos locais e alimentos na praia, em barracas, bares e restaurantes. O extrativismo é praticado pela comunidade como complemento de renda e como fonte de alimento pelo consumo das frutas nativas.

A praia de Pedra do Sal apresenta inúmeros atrativos de interesse para a população residente bem como os visitantes, destacando assim o interesse que os moradores dão às rochas, notando o valor cultural e ambiental inegáveis do promontório rochoso, de interesse para o desenvolvimento do Geoturismo para a área. As duas faixas praiais distintas (praia brava a leste e praia mansa a oeste), também se constituem em um importante atrativo para a população e turistas, entendendo assim a relação de identidade da população com a praia em questão, sendo também atrativo para a prática geoturística. Deve-se ressaltar que, tanto as rochas como as duas faixas praias citadas como principais atrativos da praia, se constituem como elementos geológico-geomorfológicos, sendo, portanto, de interesse para o geoturismo.

Em conversas informais com os moradores da praia, estes relataram que há tempos atrás esta era bem mais conservada, em todos os aspectos, o promontório rochoso não era pichado (fig.04) e as pessoas valorizavam e conservavam mais, não existia a quantidade de lixo espalhado na praia que existe hoje e até a quantidade de bares e restaurante era menor, refletindo assim em um menor impacto na praia. A questão da presença do Parque Eólico também trouxe mudanças negativas como a diminuição da vegetação da área. 


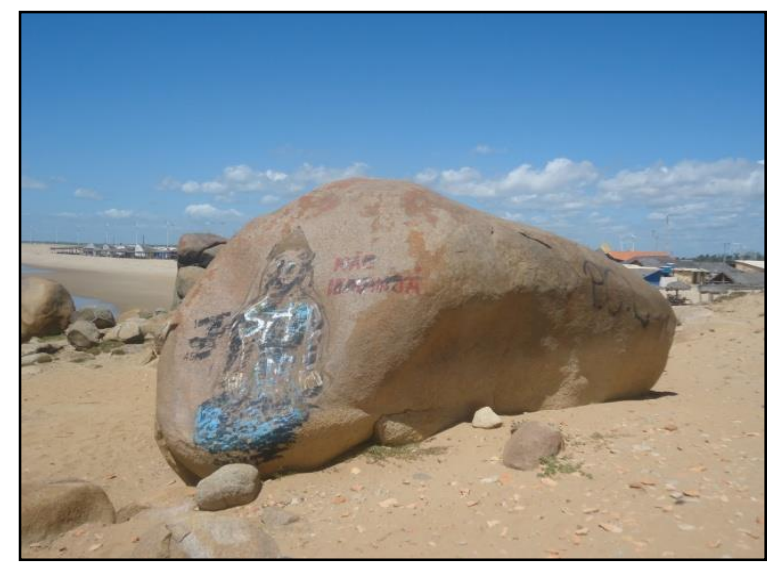

Figura 04. Rocha pichada. Fonte: Silva (2016)

No aspecto referente à contribuição da prática turística em geral para a conservação da praia em si, foi citado pela maioria da população e turistas que pode existir contribuição, mas desde que seja um tipo de turismo sustentável e que leve em conta o desenvolvimento local e o respeito pela comunidade, sendo o geoturismo adequado a esta finalidade. Também foi relatado que deve haver planejamento e organização no tipo de turismo a ser desenvolvido na praia, devendo este não ser apenas uma atividade turística que induza ao lazer, consumo e apreciação da paisagem, mas que possibilite a ideia de conservação, educação ambiental e desenvolvimento sustentável para os próprios moradores e principalmente para os turistas, que envolva a comunidade local nas atividades a serem realizadas, bem como uma maior aproximação com os órgãos competentes de fiscalização ambiental.

No que diz respeito ao conhecimento do termo geoturismo, grande parte dos moradores responderam que não sabem o que significam e que nunca ouviram falar a respeito. Nota-se então o desconhecimento por parte dos moradores da praia acerca do termo geoturismo, destacando a importância e necessidade do presente trabalho como divulgação da prática geoturística. Semelhante a população da praia, boa parte dos turistas respondeu que não sabe o que significa, desconhecendo assim a temática. O desconhecimento do termo pode ser em função da recente sistematização da temática e poucas pesquisas na área, necessitando assim de incentivos a novas pesquisas e produções referentes ao geoturismo, Geoconservação e áreas afins. Destaca-se também a confusão observada no termo geoturismo, pois quando perguntado aos residentes, estes associam o prefixo "geo" à Geografia, quando na verdade conforme Rodrigues (2008) esse prefixo relacionase ao estudo da Geologia e não da Geografia.

Por fim, obteve-se como sugestões para uma melhor conservação da praia de Pedra do Sal, inúmeras mudanças, principalmente no que diz respeito a uma coleta seletiva de lixo constante, 
incentivo à realização de campanhas de conscientização para a população e turistas no que diz respeito à valorização das rochas e a conservação das duas faixas praiais, bem como a implantação de painéis e placas de sinalização e informações acerca dos atrativos e potencialidades que a praia apresenta, sendo esta última sugestão de interesse para a implementação do geoturismo na referida praia.

Assim como a população residente da praia, os turistas e visitantes também apresentaram inúmeras sugestões para uma melhor conservação da praia de Pedra do sal, dentre elas as mais significativas foram a distribuição de depósitos para lixo na praia para evitar a quantidade de resíduos que é espalhado na praia, a realização de iniciativas voltadas para a educação ambiental para os turistas, como palestras e confecção de placas e painéis informativos sobre a praia, bem como a presença de guias turísticos para auxiliar e orientar os turistas a respeito de informações sobre os elementos naturais da praia em si e na região.

\subsection{Viabilidade do Geoturismo na praia de Pedra do Sal}

A praia de Pedra do Sal apresenta um inegável potencial para o desenvolvimento da atividade geoturística, entretanto, necessita de mais estudos e interesses voltado para a área em questão. Seus atributos geológicos e geomorfológicos, como o promontório rochoso, se constitui como o atrativo geoturístico mais evidente, e por isso, deve ser mais protegido e conservado, além das duas faixas praiais com dinâmicas distintas (praia mansa a oeste e praia brava a leste) que definem uma singularidade para a área.

Para que de fato o geoturismo como estratégia geoconservacionista seja implementado na praia de Pedra do Sal, sugere-se a realização de quatro etapas ou fases necessárias a este processo, como a elaboração de planejamento e gestão ambiental, inventário do patrimônio natural (geológico e geomorfológico), gerenciamento e por fim a etapa executiva do processo, com a construção de painéis e placas ilustrativas e informativas sobre a praia.

A elaboração do planejamento e gestão ambiental seria a realização do estudo sobre a conservação atual da praia, pesquisando quais mudanças e transformações pelas quais a área passou e passa atualmente, os principais atrativos geológicos e geomorfológicos que esta apresenta, e como a comunidade local da área ajudará e se beneficiará com a prática geoturística.

A inventariação do patrimônio natural se constituiria numa etapa fundamental na aplicação da estratégia de geoturismo com fins para a geoconservação, uma vez que permitiria a identificação e caracterização dos elementos que representam a geodiversidade da praia de Pedra do Sal 
(promontório rochoso, as faixas praiais, etc), que merecem ser quantificados, classificados, valorizados e protegidos, atrelados a valorização e conservação dos recursos bióticos da área.

Na sequência têm-se a etapa de gerenciamento, que seria a articulação entre os órgãos competentes para a viabilização do geoturismo na praia, com parcerias da prefeitura da cidade, IBAMA, ICBbio e, pesquisadores e estudantes com experiência na temática, bem como o envolvimento da comunidade local nas atividades geoturísticas.E por último, a implementação dos meios interpretativos personalizados (aqueles que dependem do auxílio de outro ser humano como excursões, guias, palestras, práticas de campo) e não personalizados (que dependem do auxílio de objetos como material impresso, exposições, painéis interpretativos, maquetes e websites).

\section{CONSIDERAÇÕES FINAIS}

Evidencia-se dessa forma o potencial geológico e geomorfológico existente na praia de Pedra do Sal, que possui atrativos geoturísticos de interesse para a geoconservação, como o promontório rochoso, atributo que mais chama atenção dos turistas e visitantes da praia, e duas faixas praiais distintas, que conferem à praia um caráter diferenciador e exclusivo da paisagem local.

Infere-se a partir dos resultados obtidos, que a praia de Pedra do Sal em relação aos seus aspectos naturais, já foi bem mais conservada, sofrendo atualmente várias transformações como o aumento da quantidade de lixo, aumento do número de bares e restaurantes, a vinda de pessoas de outros lugares a residirem na praia, a implantação do Parque Eólico que trouxe inúmeros impactos negativos para a comunidade local, e principalmente as pichações nas rochas ocasionadas pelos próprios moradores e turistas que frequentam a praia.

Obteve-se ainda como os principais atrativos da praia, as duas faixas praiais distintas sendo uma mais calma e a outra mais agitada, o farol, o pôr do sol, a rusticidade da praia, e como mais citado, as rochas que as circundam. A maioria dos participantes da pesquisa sugeriram que para uma melhor conservação da praia, deveria ser implementado um novo tipo de turismo que viabilizasse ideias de proteção ambiental, sendo o geoturismo adequado a essa finalidade. Demonstrou-se também que uma parcela dos participantes desconhecia a existência do termo geoturismo, consequentemente não sabiam o significado da temática em questão, necessitando de uma maior divulgação da proposta.

Dessa forma, a viabilização do geoturismo na praia de Pedra do Sal como possibilidade de conservação dos atrativos geológicos e geomorfológicos, deve ser analisada através de algumas etapas de planejamento adequadas à localidade, dando destaque para a construção de placas e 
painéis ilustrativos e informativos, bem como os folders e cartilhas educativas, sobre as potencialidades que a praia apresenta.

Deve-se enfatizar que a possibilidade da prática de geoturismo, seria significativa para a conservação dos recursos naturais da praia de Pedra do Sal, pois a partir deste, poderia existir uma maior valorização de seus atributos naturais, destacando os aspectos geológicos e geomorfológicos, por parte dos moradores e turistas que a frequentam, que passariam a conhecer e compreender os motivos pelos quais a praia deve ser protegida e conservada.

\section{REFERÊNCIAS}

BAPTISTA, E. M. C. Caracterização e Importância Ecológica e Econômica dos Recifes da Zona Costeira do estado do Piauí. Dissertação de Mestrado apresentada ao Programa de Pósgraduação em Desenvolvimento e Meio Ambiente da Universidade Federal do Piauí / UFPI, 2004. 289 p.

BAPTISTA, J. G. Geografia física do Piauí. Teresina: COMEPI, 1981. 363 p. FUNDAÇÃO CEPRO. Macrozoneamento Costeiro do Estado do Piauí. Teresina, 1996. 221 p. GAMA JUNIOR, T.; GORAYEB, P. S. S; ABREU, F. A. M. O Granito Pedra do Sal e suas feições de cisalhamento. Revista Brasileira de Geociências, n. 18. Belém: 1988.

IBIAPINA, M. M.; SILVA, D. A. S.; SOUSA, R. S.; ASSIS, E. G. A ampliação da Usina Eólica na comunidade da Pedra do Sal - PI: uma abordagem sócio turística. In: CONGRESSO NACIONAL DE EDUCAÇÃO AMBIENTAL, 3; ENCONTRO NORDESTINO DE BIOGEOGRAFIA, 5, João Pessoa, Anais ..., 2013. João Pessoa: p. 15-21.

MORAES, A. C. R. Contribuições para a Gestão da Zona Costeira do Brasil: Elementos para uma Geografia do Litoral Brasileiro. 2 ed. São Paulo: Annablume, 2007. 232 p.

PEREIRA, L. C. C.; JIMENÉZ, J.; MEDEIROS, C. Environmental Degradation of the Littoral of Casa Caiada and Rio Doce, Olinda (PE), Brazil. Journal of Coastal Research. Itajaí: 2003.

REIS, E. B.; BAPTISTA, E. M. C. Praia de Pedra do Sal: um olhar da paisagem e sua organização espacial. In: SIMPÓSIO DE GEOGRAFIA DA UESPI, 13, Teresina, Anais...., 2012. Teresina: p. 55-57.

RODRIGUES, J. C. Geoturismo: uma abordagem emergente. In Geoturismo \& Desenvolvimento Local. Idanha-a-Nova (Portugal), Redes, 2008.

SILVA, M. M. M. O Turismo nas ondas do litoral e das políticas públicas do Piauí. Tese de Doutorado apresentado ao Programa de Pós Graduação em Geografia da Universidade Federal de Minas Gerais / UFMG, 2013. 198 p. 


\section{AGRADECIMENTOS}

Este artigo é decorrente de diferentes momentos de estudos e pesquisas realizadas sobre e no litoral piauiense, inserindo-se nas atividades de investigação do Núcleo de Estudos sobre a Zona Costeira do Estado do Piauí - NEZCPI da Universidade Estadual do Piauí - UESPI, ao qual as autoras expressam seus agradecimentos.

Recebido em: 14/08/2016

Aceito para publicação em: 01/10/2016 